\title{
Elaborating Procedural Texts and Videos of Indonesian Culinary to Enhance Speaking Performances
}

\author{
Yuli Astuti Hasanah ${ }^{1}$ \\ ${ }^{1}$ State Islamic Institute of Kediri (IAIN Kediri), Kediri, Indonesia
}

\begin{tabular}{|l|l|l|l|}
\hline Contact: & Yuli Astuti Hasanah & $\bigotimes$ & yulihasan@iainkediri.ac.id \\
\hline
\end{tabular}

\begin{abstract}
The study described how the elaboration of creating procedural texts and videos of Indonesian culinary was used in selected EFL speaking classes in Kediri, Indonesia. The subjects of the research were the second-semester college students of IAIN Kediri. The researcher found that students had low performances in the speaking class. Classroom action research was applied to the study. The instruments used to collect the data were field notes, questionnaires, and interviews. Then, the data were analyzed descriptively. The result of the study identified that students increased collaboration of group working, confidence, learning motivation, and creativity. The study resulted those problems in speaking English could be solved through this technique. This study implies that the students improved their speaking performances by demonstrating procedural texts of making Indonesian culinary and recording them into videos that could be deliberately spread out through the YouTube website to share as valuable sources of knowledge and tutorials.
\end{abstract}

\section{KEYWORDS:}

Procedural texts, videos, speaking, classroom action research.

\section{Introduction}

Procedural texts were commonly taught by teachers or lecturers to assess their writing ability. It was ubiquitous to write a text of procedures of making or doing something. The procedural texts are written or made by thinking in mind and writing it into procedures. In this practice, the students were not exposed to the actual practice of the procedures in which, for audiovisual and kinesthetic learners that could be a bit difficult to study the lessons abstractly. In addition, teaching procedures could measure the writing skill and the speaking skill through the product of procedural writing and the act on how to make or do the procedures. 
Related to this study, the writer chooses some literature about previous research relevant to the teaching of writing procedure text. First, Huda (2015)'s thesis entitled Improving Students' Ability in Writing Procedure Text through Demonstration (a Classroom Action Research with Seventh Grade Students of MTs AI Islam Jepara in the Academic Year of 2014/2015 showed that the background of the study are that student have difficulties in writing procedure text because the teacher just explains the material orally without being supported by teaching aids. Thus, the result of the students' ability to write is low. To improve students' ability in writing procedure text, the teacher needs a strategy by using an aid that facilitates writing procedure text. Demonstration is one of the aid that can be used in teaching writing procedure text. Using realia, students can write procedure text easily. This research is classroom action research. It was done through two cycles with different types of demonstration, subject, data collection and analysis technique. The result of this research shows that students' ability was improved in each cycle after they were taught using demonstration and better in their procedure text's writing. It was signed by their improvements of each writing component, i.e.: content, organization, vocabulary, language use and mechanic. The similarity between his research and the writer is on the participation, skill focus of the study (writing), and the kind of text.

Second, Faizah (2015), in her thesis entitled Improving students' Ability in Writing Procedure Text By Using Picture (an Experimental Research at 9th Grade of MTs Nahdlatusy Syubban Sayung Demak in the Academic Year of $2014 / 2015$, showed that the background of the study in this research is based on the students' difficulties in comprehending writing procedure texts since in the teaching and learning process the teacher only explains what the procedure texts are. To develop this skill, the teacher needs strategy through a medium that will make students enjoy and easy to write. Picture is a medium that can be used in teaching writing procedure texts. 
The problem of this research can be stated as following question: 1) How well does picture give a contribution to teach procedure text to the ninthgrade students of MTs Nahdlatusy Syubban Sayung Demak in the academic year of 2014/2015. 2) Are there any differences in writing procedure text achievement between students taught using pictures and those taught using the traditional method of ninth-grade students of MTs Nahdlatusy Syubban Sayung Demak in the academic year of 2014/2015? Its purposes are: 1) To describe how well pictures contribute to teaching procedure text of the ninth-grade students of MTs Nahdlatusy Syubban Sayung Demak in academic year 2014/2015. 2) To search whether there are different effects on writing procedure text achievement between those taught using pictures and those taught using the traditional method. Based on the finding, the writer assumes that pictures may be used as an alternative medium in teaching procedure writing. The researcher here has the title of Improving The Student's Ability In Writing Procedure Text Through Demonstration (A Classroom Action Research with of Seventh Grade Students of MTs. Al Islam Jepara in the Academic Year of 2014/2015). This research has the same skill as the two theses above. The researcher wants to improve students' ability to write procedure text using demonstrations involving their content, organization, vocabulary, grammar, and mechanics. So, the researcher hopes that this research can fill in the gap in teaching writing procedure text.

Moreover, from the previous study, it was found that most students had many difficulties in speaking English as they were rarely exposed to practices in pronunciation and performances. The preliminary test of students speaking skills showed low scores which more than half of the students got under 70 . The pre-test were taken accidentally in the first meeting of speaking class by asking the students to introduce themselves orally in front of the class. More than half of the students still had some difficulties in speaking English. The difficulties faced by the students mostly 
were about the difficulty to express about the idea in mind into speaking clues, the lack of vocabulary to express their speaking, the less exposure in practising their speaking skills, the lackof English fluency and mastery, and the psychological problems in speaking English in public such as being unconfident, shy, and nervous. Therefore, as an educator, by considering the multiple characteristics of learners and the need on speaking exposures, the researcher tried to find a technique or strategy that fits all students' needs. Thinking out of the box, the researcher was interested in integrating procedural text writing with students speaking performances through oral presentation and video projects. The theme for the procedures was Indonesian culinary as to familiarize its local wisdom and promote it internationally. In short, the research question of this study was formulated as follows: How can the elaboration of procedural texts and videos on Indonesian cuisine enhance students' speaking performance? The purpose of conducting this research was encouraging the learners to create procedural videos on Indonesian culinary which elaborates the process of writing procedural texts, creating the videos using technology (i.e., Android mobile phone for taking pictures, recording videos, editing, revising the final project through Play Store applications such as Viva Video, Video Maker, etc), and presenting oral presentation on the results.

Procedural texts contain a series of instructions designed to reach a goal. Walter (2015) defined three different procedural texts for different purposes, namely: 1) Texts that explain how something works or how to use instruction/operation manuals, for example, how to use the video, the computer, the photocopier; 2) Texts that instruct how to do a particular activity, for example, recipes, rules for games, science experiments, road safety rules; and 3) Texts that deal with human behaviour, for example, how to live happily, how to succeed. Additionally, in procedures, the generic text structure is generally classified as three main parts: The first is goal which is a statement of what is to be achieved, i.e. How to make a sponge cake. 
The second is materials/equipment needed, listed in order, for instance. 2 eggs, flour. The third is sequenced steps to achieve the goal, for instance Cream the sugar and butter. Moreover, the language features of procedures are written in the imperative (Sift the flour or first you put ...) and arranged in chronological order (First, next, finally). They also use numbers, alphabet or bullet points, and color to signal order, adverbs, and adjectives for precision (measure carefully).

Furthermore, this study also used technology, especially the use of mobile phones, to produce video projects such as recording videos, taking photos, and editing. Pim (2013) stated that in the past, technology has predominately been used to source and consume information. In contrast, today's learners have become particularly adept at creating and collaboratively developing content for a wide variety of purposes, for example, so-called Web 2.0 tools such as blogs, forums and wikis. Smart devices (both phones and tablets) feature dedicated software applications (apps) that can be used to assist language learning (Pim, 2013).

Therefore, like or not, technology has been part of our lives. Also, in the dynamical development of education, technology plays the crucial parts in the challenges of the globalization era. Besides, the use of technology itself provides several benefits in accordance with the teaching learning process. According to Kern (2013), he stated that ESP teachers today cannot afford not to integrate technology into their courses, because technology plays an essential role in their learners' everyday professional lives, in which they need digital and electronic literacy skills to communicate internationally across cultural borders using different media and to become autonomous learners who can keep up with the fast-paced professional world. The reason for using technology is not only or always because it makes learning the language more effective or efficient, but also because it can offer tools that simulate real-life work situations while allowing students to acquire and practice essential 21 st century professional skills. Additionally, Basiel and 
Stannard (2013) stated that technology does not only help with what we assess; it can even help us produce relevant materials for assessment, the appropriate technology which fits the assessment criteria will broaden your assessment base, and ICT (or Information and Communication Technology) can offer great affordances to assessment.

Moreover, the elaboration of procedural texts, videos of Indonesian culinary, and oral presentation of the results were reflected as Performance Based Assessment (PBA). McLellan (2008) promoted the beneficial use of PBA in the teaching-learning process. Firstly, PBA allows a more authentic assessment of student learning outcomes. It is useful to document proficiency in applying knowledge to authentic situations. Secondly, it incorporates the skills of teaching dispositions which provides a means to approach the formative assessment of procedural knowledge. Thirdly, it provides a format to address the performance of complex tasks. Overall, performance-based assessment tools provide a promising strategy for assessing student learning in higher education.

\section{Method}

The method used in this study was classroom action research (CAR). Action research was chosen basically because the researcher intended to improve the teaching and learning process, which then was reflected by the action taken. A study conducted by O'Connor et al. (2006) examined the experiences and insights of 34 graduate students in an elementary education master's degree program as they engaged in an action research project, showed that the role action research might play in creating positive change in teachers' practices. It started by recognizing problems that appeared in the researcher's speaking class. The problem was that the low scores of students' speaking test which were under 70 and that the students had fewer experiences of performing English in public, low confidence, and hesitance which thus those obstacles affected their speaking scores to low 
grades. Considering some references of alternative strategies, the researcher initiated to combine the procedural texts and videos as the teaching strategy. The subject of the study is the second-semester college students of STAIN Kediri in the academic year of 2016/2017. The instruments used to collect data were field notes, questionnaires, and interviews. The criteria of success for this study was 75 or grade $B$ as it was categorized to pass the course reasonably. Below are the procedures of the implementation, which are divided into several subsections: planning the course, procedures of classroom activities, and reflection on results.

\section{Finding and Discussion}

\section{Planning the course}

In planning, the researcher made a lesson plan for five meetings. The course requires a series of processes, including identifying procedural texts, writing procedural texts of Indonesian culinary, presenting the procedures, making videos based on the procedural texts chosen, and presenting on the video projects. The teaching and learning process on identification, writing, and presentation was done in the classroom, whereas creating video projects was done beyond the classroom.

\section{Procedures of classroom activities}

The procedures of classroom activities were conducted in four meetings in the classroom and one meeting beyond the classroom for research and creating the final project. In the first meeting, the researcher explained what the objectives and outcomes of the study are. The students were taught material about procedural texts including its definition, structures, examples, and action verbs. At first, students were shown an example of procedural texts. They were asked to identify and mention the text's structures, such as the title, the materials, the equipment, and the methods. Furthermore, they concluded the definition of procedural text by considering what they had been identified previously. Next, they were given another 
example of procedural texts. For this time, the procedural text was a procedure of cooking food. They were asked to identify the structure, namely the title, the ingredients, the cooking utensils, and the steps. Then, they had known that the procedural texts might have different terms of structures for different purposes. In addition, they were also shown some action verbs used in procedural texts of cooking food such as peel, dry, cut, fry, boil, chop, serve, slice, stir, mix, blend, bake, roast, spread, and so forth. They were given a worksheet to match the appropriate action verbs to the correct statements to practice it. The worksheet contained five questions based on the text.

The second meeting, students were grouped into four to five people. They were given a task to create a procedural text of cooking. The topic was about Indonesian culinary. They discussed within the group and started making drafts for 30 minutes. After finished, each group presented the procedural text. The lecturer revised and gave feedback on their work. Then, they revised the texts. For the next meeting, the lecturer asked each group to perform the procedural texts they had made into the next class presentation. They were announced to bring the ingredients and cooking utensils for the practice. Task presentation lasted for 10-15 minutes.

The third meeting was the class presentations. Each group had to perform their cooking performances. Each member of the group had to show equal opportunity to demonstrate what they were going to do and make starting from opening the presentation, introducing the members, telling the ingredients, and cooking utensils needed, showing the procedures of cooking step by step, and closing. The lecturer evaluated and gave feedback on the students' performances through three aspects: content on procedures, innovation, and creativity on videos, and speaking performance on presentations. The feedbacks were used by the students to be evaluated for the next presentation on the final project of making procedural videos. 
The fourth was done beyond the classroom. In this step, students were assessed to create videos of cooking. They were asked to record their speaking performance of practicing procedural text and recorded it into videos. After finished, they could edit and submit as the final task. Next, in the fifth meeting, each group had to present the results of the video project in front of the class. The students' speaking performances were assessed through three aspects, namely: content on procedures, innovation, and creativity on videos, and speaking performance on presentations. Furthermore, the results of students' videos were uploaded by the lecturer in YouTube and can be accessed in the researcher's channel: Yulia Hasanah at https://www.youtube.com/channel/UCOiqfjBHxBuCuJqQFRB67Fg.

\section{Reflection on Results}

The reflection was done through the students' speaking scores, questionnaires, and interviews. The students' speaking scores covered three aspects to be measured: content on procedures, innovation and creativity on videos, pronunciation, and fluency and mastery on speaking performances. The speaking rubrics were as follows in the Table 3.1:

Table 3.1 The Speaking Rubrics

\begin{tabular}{|c|c|c|}
\hline & Aspects & Descriptions \\
\hline 1 & $\begin{array}{l}\text { Content on } \\
\text { procedures }\end{array}$ & $\begin{array}{l}91-100=\text { very good organization (materials, tools, and steps) } \\
81-90=\text { good organization (materials, tools, and steps) } \\
71-80=\text { fair organization (materials, tools, and steps) } \\
0-70=\text { poor organization (materials, tools, and steps) }\end{array}$ \\
\hline 2 & $\begin{array}{l}\text { Innovation and } \\
\text { creativity on videos }\end{array}$ & $\begin{array}{l}91-100=\text { very highly innovative, creative and eye catching } \\
81-90=\text { highly innovative, creative and eye catching } \\
71-80=\text { fairly innovative, creative and eye catching } \\
1=\text { poorly innovative, creative and eye catching }\end{array}$ \\
\hline 3 & Pronunciation & $\begin{array}{l}91-100=\text { very good on pronunciation } \\
81-90=\text { good on pronunciation } \\
71-80=\text { fair on pronunciation } \\
0-70=\text { poor on pronunciation }\end{array}$ \\
\hline 4 & Fluency and mastery & $\begin{array}{l}91-100 \text { = very good on fluency and mastery; very highly attractive and } \\
\text { interactive } \\
81-90 \text { = good on fluency and mastery; highly attractive and interactive } \\
71-80 \text { = fair on fluency and mastery; fairly attractive and interactive }\end{array}$ \\
\hline
\end{tabular}


$0-70=$ poor on fluency and mastery; poorly attractive and interactive

The students' scores are as follows in the Table 3.2 and the frequency distribution of the students' speaking scores could be seen in the Table 3.3.

Table 3.2 The Students' Speaking Scores

\begin{tabular}{|c|c|c|c|c|c|c|c|}
\hline No & Name & 1 & 2 & 3 & 4 & Total Scores & Grade \\
\hline 1 & $\mathrm{AFH}$ & 93 & 90 & 94 & 90 & 92 & $\mathrm{~A}$ \\
\hline 2 & DAA & 87 & 90 & 80 & 83 & 85 & $\mathrm{~B}+$ \\
\hline 3 & SEY & 82 & 90 & 75 & 83 & 83 & $\mathrm{~B}+$ \\
\hline 4 & STA & 87 & 90 & 79 & 80 & 84 & $\mathrm{~B}+$ \\
\hline 5 & AM & 96 & 90 & 83 & 85 & 89 & A- \\
\hline 6 & $\mathrm{BA}$ & 92 & 90 & 78 & 86 & 87 & A- \\
\hline 7 & FW & 87 & 90 & 83 & 78 & 85 & $\mathrm{~B}+$ \\
\hline 8 & SM & 86 & 90 & 82 & 86 & 86 & A- \\
\hline 9 & YAM & 90 & 90 & 88 & 86 & 89 & A- \\
\hline 10 & $\mathrm{YNH}$ & 92 & 90 & 80 & 78 & 86 & $\mathrm{~B}+$ \\
\hline 11 & LNF & 92 & 90 & 91 & 86 & 90 & A- \\
\hline 12 & MWP & 90 & 90 & 86 & 86 & 88 & A- \\
\hline 13 & $\mathrm{HM}$ & 91 & 90 & 60 & 71 & 80 & $\mathrm{~B}$ \\
\hline 14 & IA & 94 & 90 & 88 & 86 & 90 & A- \\
\hline 15 & $\mathrm{HL}$ & 93 & 90 & 86 & 71 & 85 & $\mathrm{~B}+$ \\
\hline 16 & ADS & 92 & 90 & 95 & 88 & 91 & $A$ \\
\hline 17 & KS & 83 & 90 & 72 & 86 & 83 & $\mathrm{~B}+$ \\
\hline 18 & MAN & 93 & 90 & 70 & 86 & 86 & $\mathrm{~B}+$ \\
\hline 19 & NKN & 94 & 90 & 80 & 86 & 88 & A- \\
\hline 20 & LV & 91 & 90 & 83 & 71 & 84 & $\mathrm{~B}+$ \\
\hline 21 & KCA & 89 & 90 & 67 & 71 & 80 & $\mathrm{~B}$ \\
\hline 22 & KDY & 91 & 90 & 79 & 83 & 86 & A- \\
\hline 23 & MSM & 87 & 90 & 85 & 90 & 88 & A- \\
\hline 24 & MZA & 70 & 90 & 75 & 85 & 80 & $B$ \\
\hline 25 & GEW & 93 & 80 & 87 & 78 & 85 & $\mathrm{~B}+$ \\
\hline 26 & KRP & 92 & 90 & 82 & 86 & 88 & A- \\
\hline 27 & YAI & 87 & 90 & 80 & 83 & 85 & $\mathrm{~B}+$ \\
\hline 28 & PEE & 87 & 90 & 76 & 83 & 85 & $\mathrm{~B}+$ \\
\hline 29 & MMR & 90 & 90 & 75 & 83 & 85 & $\mathrm{~B}+$ \\
\hline 30 & $\mathrm{OM}$ & 83 & 90 & 77 & 90 & 85 & $\mathrm{~B}+$ \\
\hline 31 & $A A$ & 96 & 80 & 80 & 80 & 85 & $\mathrm{~B}+$ \\
\hline 32 & MAK & 92 & 90 & 82 & 83 & 87 & A- \\
\hline 33 & ER & 91 & 90 & 80 & 83 & 87 & A- \\
\hline 34 & $\mathrm{EL}$ & 86 & 90 & 84 & 83 & 86 & $\mathrm{~B}+$ \\
\hline
\end{tabular}

Table 3.3 The Frequency Distribution of the Students' Speaking Scores

\begin{tabular}{llccccc}
\hline \multicolumn{1}{c}{$\begin{array}{c}\text { Students' Speaking } \\
\text { Scores }\end{array}$} & Score $\mathbf{9 1 - \mathbf { 1 0 0 }}$ & $\begin{array}{c}\text { Score 81 } \\
-\mathbf{9 0}\end{array}$ & $\begin{array}{c}\text { Score 71 } \\
-\mathbf{8 0}\end{array}$ & $\begin{array}{c}\text { Score 0 0 } \\
-\mathbf{7 0}\end{array}$ & TOTAL \\
\hline Content on procedures & Frequency & 18 & 15 & 1 & 0 & 34 \\
\cline { 2 - 7 } & \%f & $53 \%$ & $44 \%$ & $3 \%$ & $0 \%$ & $100 \%$ \\
\hline $\begin{array}{l}\text { Innovation and } \\
\text { creativity on videos }\end{array}$ & Frequency & 0 & 32 & 2 & 0 & 34 \\
\cline { 2 - 7 } & & $0 \%$ & $94 \%$ & $6 \%$ & $0 \%$ & $100 \%$ \\
\hline Pronunciation & Frequency & 3 & & & & 3 \\
\hline
\end{tabular}




\begin{tabular}{llccccc}
\hline & $\% \mathrm{f}$ & $9 \%$ & $38 \%$ & $44 \%$ & $9 \%$ & $100 \%$ \\
\hline Fluency and mastery & Frequency & 1 & 23 & 10 & 0 & 34 \\
\hline & $\% \mathrm{f}$ & $3 \%$ & $68 \%$ & $29 \%$ & $0 \%$ & $100 \%$ \\
\hline
\end{tabular}

The results on the students' scores showed that $97 \%$ of the students reached good organization (materials, tools, and steps), 94\% of the students reached highly highly innovative, creative and eye-catching videos, $82 \%$ of the students reached fairly and good pronunciation in the speaking performance on presentations, and $97 \%$ of the students reahed good on fluency and mastery and highly attractive and interactive on presentations. Therefore, it was concluded that $15 \%$ of the students reached grade $A$ or excellent, $79 \%$ of the students reached grade $A$ - and $B+$ or very good satisfaction, and $6 \%$ of the students reached grade $B$ or good satisfaction as seen in the Figure 3.1 below.

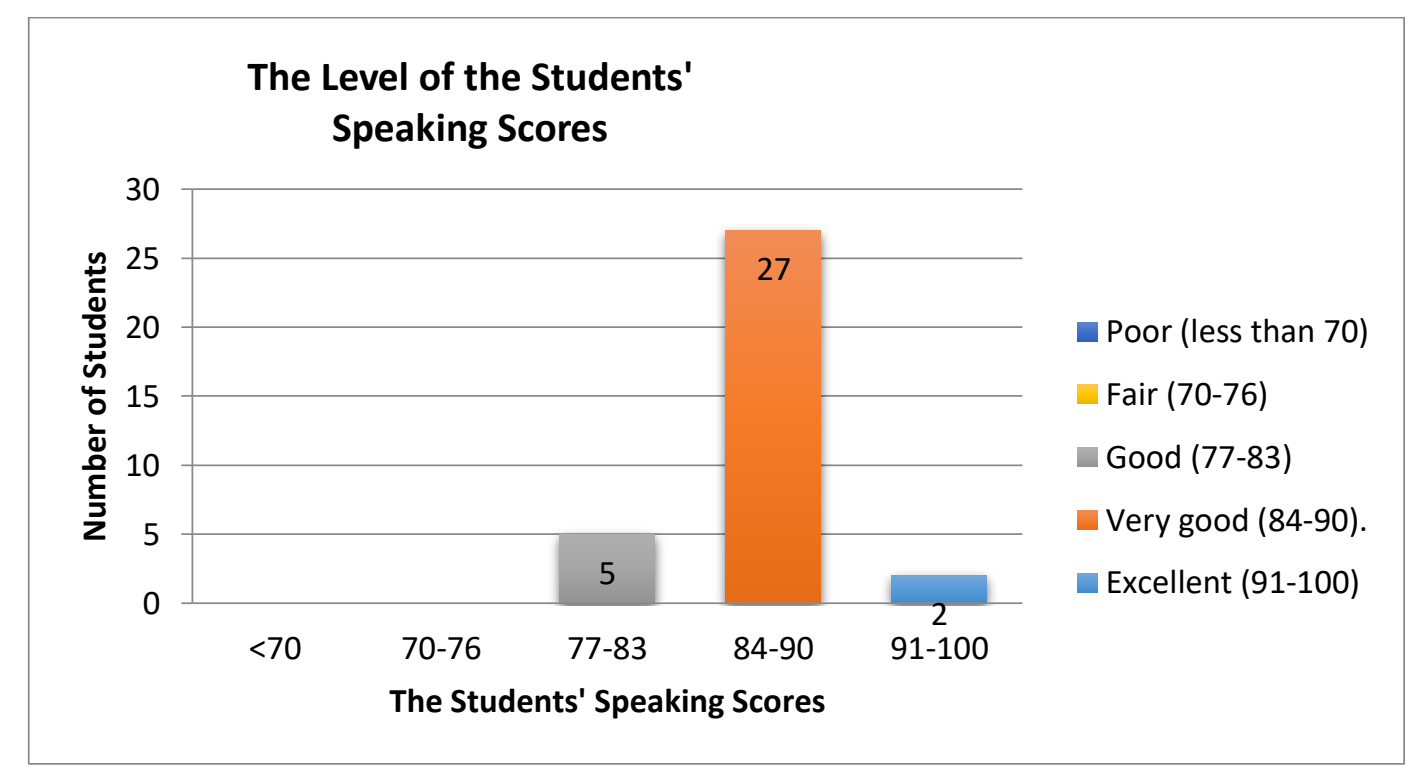

Figure 3.1 The Level of the Students' Speaking Scores

Then, in the end of study, the students were interviewed and asked to fill in the questionnaire by giving check to the column to evaluate the teaching and learning process. The questionnaires contained five questions which responded to the strategy of using procedural text and video projects as follows in the Table 3.4: 
Table 3.4 The Students' Questionnaire

\begin{tabular}{|c|c|c|c|c|c|c|c|}
\hline No & Questions & 1 & 2 & 3 & 4 & 5 & Comments \\
\hline 1 & $\begin{array}{l}\text { The strategy of elaborating procedural texts and } \\
\text { videos on Indonesian culinary raises my } \\
\text { confidence to speak up. }\end{array}$ & & & & & & \\
\hline 2 & $\begin{array}{l}\text { The strategy of elaborating procedural texts and } \\
\text { videos on Indonesian culinary can improve my } \\
\text { speaking fluency. }\end{array}$ & & & & & & \\
\hline 3 & $\begin{array}{l}\text { The strategy of elaborating procedural texts and } \\
\text { videos on Indonesian culinary gains group working } \\
\text { and cooperative learning. }\end{array}$ & & & & & & \\
\hline 4 & $\begin{array}{l}\text { The strategy of elaborating procedural texts and } \\
\text { videos on Indonesian culinary creates good } \\
\text { atmosphere of English class. }\end{array}$ & & & & & & \\
\hline 5 & $\begin{array}{l}\text { The strategy of elaborating procedural texts and } \\
\text { videos on Indonesian culinary is a good strategy to } \\
\text { be applied in teaching and learning process. }\end{array}$ & & & & & & \\
\hline
\end{tabular}

Scale:

Very poor / very low

Poor / low

Fair / enough

Good / high

Very good / very high

In addition, the questionnaires distributed to all the students showed that in the first category, $80 \%$ of the students responded that students' confidence to speak up was good/high by having the strategy, and $15 \%$ was fair. For the second category on English fluency, $85 \%$ of the students responded good/high and the rest was fair. The third category on group working and cooperative learning, 100\% students voted very good/very high. Next, in the fourth category on creating good atmosphere, 100\% students responded very good/very high. At last, in the category on good strategy for the teaching-learning process, $90 \%$ students responded very good/very high, and the rest voted good/ high.

Furthermore, for the interviews were done randomly to students to know their opinions about the strategy. The followings were some comments: "I like this strategy because it's so interactive", said one student. Another added, "It's exciting to have video projects as we act like movie stars". Others said, "This English class isn't boring because we really do 
something special for the project and I really like it. I feel impressed". Most of students responded positively about the strategy since it gave the students opportunities to explore their potentials. The strategy also stimulated the students to be creative and active by having the video projects. They were so excited and enjoyed on having the task with no burden.

\section{Conclusion and Suggestion}

It can be summed up that the students' performance through procedural videos showed positive results in improving students' performances skills. It can be shown that the students have reached excitement and confidence in speaking English and can enhance their creativity in speaking class. The students become active in exploring their English skills, especially in speaking. Therefore, it is highly suggested for lecturers, teachers, and educators to apply this technique in the teaching and learning process to solve the same problem and enrich the variety of good techniques during the English class. For the further researcher, this technique possibly can be combined to other materials and skills related to the study.

\section{References}

Basiel, A., \& Stannard, R. (2013). A Practice-Based Exploration of Technology for English Language Teaching and Enhanced Assessment in Innovations in Learning Technologies for English Language Teaching (Gary, Mott). London: British Council.

Faizah, L. (2015). Ability In Writing Procedure Text By Using Picture (an experimental research at the 9 th grade of MTS Nahdlatusy Syubban Sayung Demak in the Academic Year of 2014/ 2015)". Walisongo State Islamic University (UIN) Semarang, Semarang. Retrieved from http://eprints.walisongo.ac.id/5098/1/113411128.pdf

Huda, M. M. (2015). Improving Students' Ability in Writing Procedure Text through Demonstration (A Classroom Action Research with the Seventh Grade Students of MTs Al Islam Jepara in the Academic Year of 2014/2015). Walisongo State Islamic University (UIN) Semarang.

Kern, N. (2013). Technology-Integrated English for Specific Purposes Lessons: Real-Life Language, Tasks, and Tools for Professionals in Innovations in Learning Technologies for English Language Teaching (Gary, Mott). London: British Council.

McLellan, S. (2008). When Students Teach: Performance Based Assessment. Transformative Dialogues: Teaching \& Learning Journal, 2(2). 
O'Connor, K. ., Greene, H. C., \& Anderson, P. J. (2006). Action Research, A Tool for Improving Teacher Quality and Classroom Practice. East Carolina University.

Pim, C. (2013). Emerging Technologies, Emerging Minds: Digital Innovations within the Primary Sector in Innovations in Learning Technologies for English Language Teaching (Gary, Mott). London: British Council.

Walter, C. (2015). Procedural Writing. Sascatchewan School Library Association. 